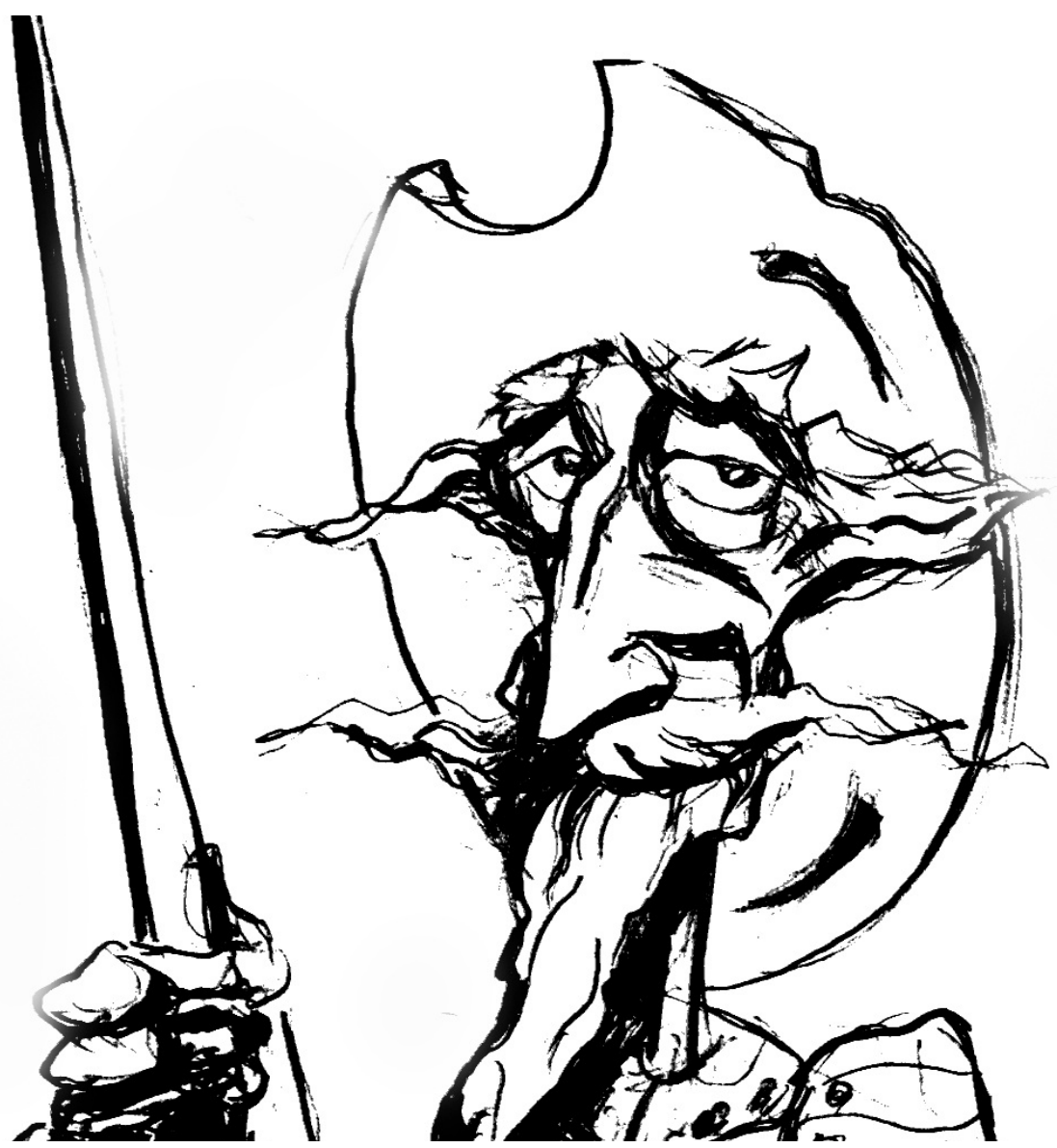

El institutional entangled global network de navarros y vascongados en la defensa atlántica por la plata peruana del Seiscientos (Madrid, Potosí y Puno)

[Alberto Angulo Morales] 



\section{El institutional entangled global network de navarros y vascongados en la defensa atlántica por la plata peruana del Seiscientos (Madrid, Potosí y Puno)*}

\section{The Institutional Entangled Global Network of Navarrese and Basque people in the Atlantic defense for the Peruvian silver of the Seventeenth century (Madrid, Potosí and Puno)}

Alberto AngUlo Morales

\section{Resumen}

Este artículo se centra en el análisis del papel colaborativo ejercido por los emigrantes vascos y navarros durante el siglo XVII en el proceso de control del negocio de la plata peruana. La colaboración entre los emigrantes, sus cofradías (en Indias y la Península Ibérica) y las autoridades de origen generó una institutional entangled global network que les permitió ejercer un alto nivel de influencia en este mercado. Una red global que mantuvo y generó un proceso de identidad comunitario de gran relevancia previo al proceso que se ha estudiado en el siglo XVIII.

Palabras clave

Emigración; Red Global; Plata; Corte;

Diplomacia; Naciones

\begin{abstract}
This article focuses on the analysis of the collaborative role played by Basque and Navarrese emigrants during the seventeenth century in the process of controlling the Peruvian silver business. The collaboration between the emigrants, their brotherhoods (in the Indies and the Iberian Peninsula) and the authorities of origin generated an institutional entangled global network that allowed them to develop a high level of influence in this market. A global network that maintained and generated a highly relevant community identity process prior to the process studied in the eighteenth century.
\end{abstract}

Key Words

Emigration; Global Network; Silver; Court; Diplomacy; Nations

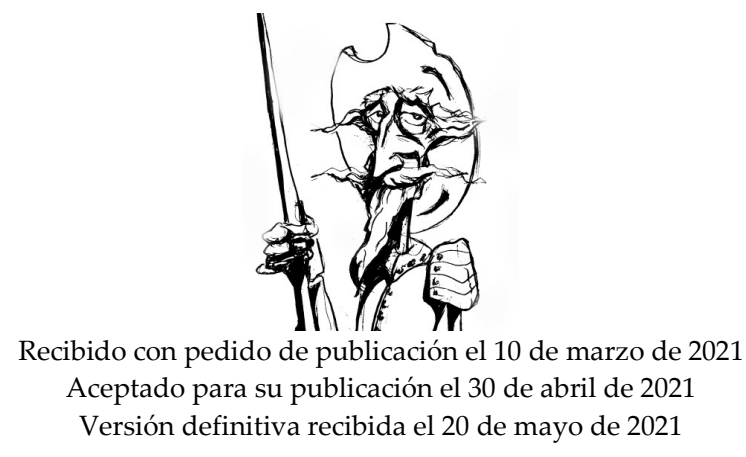

Alberto Angulo Morales, Universidad del País Vasco /Euskal Herriko Unibertsitatea, Vitoria-Gasteiz, España; e-mail: alberto.angulo@ehu.eus

* Agradezco a los evaluadores anónimos de revista Prohistoria por sus sugerencias.

Esta obra se publica bajo licencia Creative Commons. Atribución-NoComercial-CompartirIgual 4.0 Internacional 
Los estudios adheridos a la historia global frecuentan con avidez el continente de las relaciones entre los agentes históricos que integraron los mundos de nuestro pasado. ${ }^{1}$ En este marco de interpretación histórica elementos poco considerados hasta hace escaso tiempo -la comunicación, la información o la representación a escala mundial- (Gaudin, 2017; Albareda y Herrero, 2018; Yun, 2019) tienden a fijarse en paradigmas de las nuevas formas de hacer historia. En este marco, nuestra propuesta versa sobre el análisis del rol de diversos agentes históricos (individuos, familias, cofradías e instituciones) en aras de subrayar la activa colaboración que estos -mayoritariamente no estatales- ejercieron en el discurrir de un proyecto como fue la defensa de los dispares intereses de navarros y vascongados por el control de la plata en el Perú del Seiscientos.

Partiendo del concepto de global network (Herzog, 2000: 117-133) para definir la actuación de los naturales del Reino de Navarra en la Península e Indias desde fines del Seiscientos, proyectaremos una imagen sobre los mecanismos colaborativos usados por los originarios de las tierras fronterizas del norte peninsular buscando institucionalizar una defensa vertebrada en Madrid mediante sus agencias y embajadas en Corte (Angulo, 2016: 261-296). A nuestro entender y al calor de la actividad de las naciones-patrias de tiempos de los Habsburgo, entendemos más conveniente hablar de la existencia de un institutional entangled global network. En esencia, la comunicación y colaboración entre los emigrantes, las asociaciones de naturales y las autoridades de los territorios de origen explican mejor la política migratoria de los naturales de las tierras pirenaicas (Aragón, 2019: 452-481).

Los proyectos colaborativos entre las instituciones de los territorios de origen, una tupida red de asociaciones de naturales y su membresía es clave para entender el sentido del institutional entangled global network. Los tres actores históricos referidos buscaron espacios y momentos de acción comunes que promoviesen una política de protección atlántica de los intereses de los hombres y mujeres que partían del norte peninsular buscando fortuna. El amparo institucional se expresó en la activación de la capacidad de influencia y presión -formal e informal- que los embajadores provinciales mantuvieron en Madrid mientras las asociaciones -surgidas con el plácet de las autoridades de origen- conservaron activos unos nexos de sociabilidad y solidaridad que activaron una renovada percepción de la identidad de su membresía.

\footnotetext{
1 Trabajo realizado dentro del Grupo de Investigación Consolidado del Sistema Universitario Vasco "País Vasco, Europa y América: Vínculos y Relaciones Atlánticas" y en el Proyecto I + D del Ministerio de Economía y Competitividad "Guerra, Estado y Sociedad. La movilización de recursos militares en la construcción de la Monarquía Española en el siglo XVIII" (PGC2018096194-B-100).
} 
Esta precisión teórica va acompañada de una realidad histórica bien documentada, los numerosos conflictos protagonizados por los emigrantes vascos y navarros asentados en Indias y cuya solución se vehiculó por la vía madrileña -bien ante los consejos bien ante la Corona- en una dinámica histórica de negociación y colaboración propia de los imperios de la Edad Moderna (Greene, 2002: 267-282; Angulo, 2019: 427-458). El ansia de canalizar los intereses económicos y políticos de los emigrantes de estos espacios del norte peninsular contó con la ayuda de las cofradías y congregaciones nacionales o de naturales fijadas en los centros urbanos de la España de tiempo de los Habsburgo (Álvarez et al., 2014; Angulo, 2015: 113-139).

En diferentes medidas y tiempos, los actores salidos del Reino de Navarra, de las dos provincias vascas o del señorío de Vizcaya concretaron una identidad donde la dirección e influencia de las instituciones de sus territorios de origen resultó fundamental. La vizcainía no era un sentimiento -como la navarreness (Herzog, 2002: 127)- de pertenencia o identidad sino una poderosa realidad jurídica citada en el primer título del Fuero de Vizcaya (1575). Tal norma defendía la perdurabilidad de las franquezas y exenciones vizcaínas en cualquier posesión de la Corona.

Esta norma jurídica penetró en los corazones y mentes de los vizcaínos asentados en Sevilla, Flandes o Indias. Las condiciones del Fuero vizcaíno nunca fueron extensivas a los habitantes de las provincias hermanas o a los navarros. Cada territorio contaba con su repertorio legal. Eso sí, la confluencia de elementos culturales e idiomáticos, una tridentina catolicidad y la positiva experiencia de la creación sistémica de asociaciones de defensa mutua explican el desarrollo histórico de un sentimiento de pertenencia que superó el territorio de origen de cada emigrante. Las cofradías de Nuestra Señora de Aránzazu en Indias (Álvarez Gila y Arrieta Elizalde, 2004; Angulo, 2017: 113-133) resultó básica en la construcción de una identidad para los originarios de estos cuatro territorios ofreciendo una percepción identitaria superior a las naciones-patrias (Donézar, 2004: 93-120).

No son meros individuos o familias que pretendan utilizar estrategias propias para llegar al éxito (Pérez, 2014: 241-275) sino, más bien, de muchos segundones abocados a emigrar y que aspiran a mantener su peculiar estatuto jurídico -hidalguía universal- como base de su futuro (Arrieta, 2014: 792-842; Angulo, 2015: 113-139). La defensa de los parlamentarios del señorío de Vizcaya a fines del Quinientos estimaba que el principal activo de sus naturales no era tanto la riqueza como su nobleza o hidalguía. Esta situación generó disputas y discordias en su proceso de asentamiento en las áreas más favorables para su enriquecimiento a ambos lados de Atlántico.

Los conflictos en Perú, otras zonas americanas o la Península Ibérica entre las naciones -navarra y vascongada/vizcaína contra otras (extremeña, 
andaluza, castellana, gallega, portuguesa)- que integraban la Monarquía compuesta muestran la pervivencia de mecanismos que superaban -bien que no eliminaban- el papel de las redes tramadas por las familias más prestigiosas, ricas o relevantes de la policéntrica monarquía de los Austrias (Cardim, 2012). $\mathrm{La}$ pervivencia de las naciones-patria ofrece una clara imagen de una monarquía integrada por "repúblicas de repúblicas". El carácter compuesto de estas entidades políticas no puede ubicarse ni analizarse solo desde el prisma de su centralidad sino también desde la perspectiva de los diversos cuerpos con singular peso en las repúblicas, reinos o provincias cuya agregación integraba las monarquías o los imperios del Seiscientos. El papel de la autoridad fragmentada (Dincecco, 2010: 305-328), cuando no compartida, resulta un elemento clave a la hora de entender la relevancia de la concentración de poder que logran los institutional entangled globat networks durante el Seiscientos.

\section{Una familia atlántica: hijos de sus territorios de origen}

Las actas de las Juntas Generales de Vizcaya, Guipúzcoa y Álava emplearon la metáfora de la casa-provincia o madre-provincia como refugio y catalizador de la movilidad de sus naturales (Angulo, 2015: 113-139; Martínez Aznal, 2016: 143-168). Estos territorios se autodefinían retóricamente como repúblicas de casas (Herrero, 2017) de donde, por necesidad u obligación, los segundones estaban abocados a salir buscando fortuna. Un topos para padres y madres, vecinos, autoridades locales y futuros emigrantes provinciales fue que la movilidad generaría trabas desorientadoras capaces de hacerles perder cuerpos y almas.

La disipación de los jóvenes en el camino conllevaba la pérdida de oportunidades y chocaba con la imagen y el valor concedido a la hidalguía por sus autoridades. Unas familias que preparaban con tiento sus procesos de movilidad. Bernardo de Aguirre (1600-1674) se educó como otros hijos "de padres honrados" de Guipúzcoa que salieron "por la cortedad de la tierra" (Angulo. 2017: 113). Su formación entre Cádiz y Sevilla fue en casas de hombres de negocios guipuzcoanos y navarros; es decir, paisanos (Fernández, 2000). Aguirre fue uno más de los enviados a servir "a hombres de negocios y por este medio proveen a acaudalar y hacer hacienda" y que "han vuelto a sus tierras muy acomodados de hacienda" (Angulo, 2017:114). Con el tiempo, el joven llegado a Sevilla, Cádiz o a cualquier espacio americano con el apoyo de familiares, amigos y paisanos se convertía en un caballero con honores adquiridos en el mercado cortesano madrileño (Otazu, 2008: 177-192). El entorno social que protegía su movilidad es nota propia de las migraciones en cadena. Pero, ¿qué ocurría con los hijos de padres no tan honrados ni de tal calidad? En 1595, el sevillano de adopción pero vizcaíno de nacimiento, Pedro de Bustinza, pedía que: 
“...como a hijos e naturales suyos [...] se ordenase "a sus agentes y personajes que tiene en Madrid [...] para les ayudar en esta causa y libertad de sus personas [...] porque este daño no solo resultaría para ellos pero también para todos los venideros, y porque seria en daño notable e general y causa para perecer y perder del todo el trato e comercio que hay en la dicha ciudad de los vizcaínos y provincianos" (Angulo y Merino, 2012: 1787).

Este pasaje integra la defensa contra la edición del libro del fiscal vallisoletano Juan García de Saavedra que ponía en solfa la valía de la hidalguía universal vizcaína (Arrieta, 2014: 792-842). Las autoridades vizcaínas vieron que este argumento debilitaría el principal caudal del Señorío que, como sostenía Bustinza, no eran riquezas sino nobleza e hidalguía. El agente en Madrid, Francisco Ibáñez de Mallea, logró una cédula de Felipe II para expurgar los renglones más peligrosos del libro y proteger el estatuto jurídico de las próximas generaciones de emigrantes que no contaban con cadenas familiares que les ayudasen. Mallea (Madrid) y Bustinza (Sevilla) eligieron a los expurgadores formada por una lista de vizcaínos electos por su calidad y honor, oficiales del Rey que actuarían en las imprentas sitas en Chancillerías y Audiencias, Sevilla, los virreinatos de Perú y México, otros reinos y principados cantábricos o varias ciudades castellanas (Angulo y Merino, 2010: 1781-1791). Una misión de defensa del principio de la hidalguía universal a ambas orillas de Atlántico. Esta empresa la gestionó la legión de vizcaínos asentada en las principales ciudades de la Monarquía de los Habsburgo. El principio de reciprocidad -do ut des (Angulo y Merino, 2010: 1788)- fue el principal recurso de los aparatos políticos provinciales. Si la hidalguía universal vizcaína favorecía a sus hijos en sus procesos de movilidad, su protección sería un activo vital para sus naturales.

La provincia guipuzcoana evolucionó paralelamente hasta presentarse como una comunidad territorial definida en términos domésticos. Su parlamento usaba un lenguaje político que transmitía las estrategias domésticas de las casas solares a la comunidad política territorial. Manuel de Larramendi dibujó la provincia como un mayorazgo integrado no solo por "los primeros mayorazgos y poseedores, sino también para sus descendientes y sucesores" (Larramendi, 1983: 131). De este modo, la casa-provincia guipuzcoana velaría por la salud y conservación de las casas particulares y, en una relación de reciprocidad, los particulares devolverían el favor. A mediados del Setecientos, la diputación de Guipúzcoa era concebida como madre de sus hijos e hijas (Achón, 2001: 113-138). Y no olvidemos que los tres territorios (Álava, Guipúzcoa y Vizcaya) también comenzaron a titularse en el Seiscientos como "provincias hermanas" (Angulo, 2016). 
Si la provincia era la madre, sus naturales eran sus "hijos de la provincia", unos retoños devotos. La edición del Compendio Historial de la M. N. y M. L. Provincia de Guipúzcoa en 1625-1626 por Lope Martínez de Isasti ofrecía un listado de ochocientos servidores de la Corona, todos "hijos" provincianos. Unos vástagos educados a temprana edad en las reglas de leer y escribir para enviarlos al sur peninsular e Indias a la casa, tienda o lonja de algún familiar, socio, amigo o paisano desde donde buscar un mejor futuro. Este elenco de hijos ilustres sería el modelo para los segundones abocados a iniciar nuevos procesos de movilidad.

El Fuero Nuevo de Vizcaya (1526), dedicado a los "hijos del Señorío", regía a la comunidad política provincial dentro y fuera de su jurisdicción. Por ello, estas provincias asumieron la potestad de desnaturalizar a quienes actuasen contra sus intereses o su legislación. La Junta General de Guipúzcoa de 1517 condenó a quien sacase provisiones reales o privilegios contra sus ordenanzas a perder la mitad de su hacienda y a ser desposeídos de vecindad y naturaleza. ${ }^{2}$ En esa línea, en 1661, el Señorío amenazó con desnaturalizar a Jacinto de Romarate por atentar contra sus fueros. ${ }^{3}$ Premio o castigo eran las caras de la intervención de las autoridades provinciales. Otro ejemplo del premio lo reflejan las actas alavesas que felicitaron a Francisco Antonio de Salcedo por el título de Castilla logrado como "hijo de la provincia". ${ }^{4}$

En su calidad de hijos fueron apoyados, criticados y protegidos por las autoridades provinciales. En Valladolid y Madrid, los agentes de los tres territorios ejercieron una activa vigilancia sobre los procesos de movilidad de individuos y familias llegados de sus territorios. Esta comunicación activa y colaboración estrecha entre los emigrantes y las autoridades del terruño preparaba el camino de retorno que pululaba por sus mentes. Volver y lograr el reconocimiento de la Corona y de las autoridades territoriales permitía acceder al mercado de mercedes. Este diagrama se enriquece con el nacimiento y desarrollo de otro elemento surgido en los centros urbanos del Imperio (Sevilla, Cádiz, Potosí, Lima, México o Madrid) como fueron las asociaciones o cofradías de emigrantes por naturaleza (Álvarez, 2014).

En Lima se aposentó un vizcaíno que actuó en los mercados de inicios del siglo XVII: Juan de la Plaza. Ocupó los empleos de asentista de la Real Armada, capitán de la flota, financiero en los astilleros de Guayaquil y vendedor de navíos. Plaza obtuvo una de las siete licencias para fundar un banco con la oposición del Consulado limeño, reticente porque la legislación de época pedía que el banquero fuese persona "llana y abonada en su persona y

\footnotetext{
2 Archivo General de Simancas, Consejo de la Cámara de Castilla. L. 124/113.

${ }^{3}$ Archivo Histórico Nacional. Consejos Suprimidos. Consejo de Castilla. L. 25860/5.

${ }^{4}$ Archivo del Territorio Histórico de Álava (ATHA). Actas de Juntas Generales (AJJGG). Libro 26. $11 / 04 / 1712$, f. $13 \mathrm{v}$.
} 
sus bienes". El ser vizcaíno le eximía de ser preso por deudas (Suárez, 2001: 6970). El discurso de Plaza entremezcla reflexiones como la predisposición de los nobles a ser tanto o más llanos (puntuales, honrados, fieles y profesionales) que los plebeyos o al papel de sus compatriotas sevillanos como banqueros públicos o compradores de metales (Angulo Morales, 2012: 241-256). En su alegato sostiene que los Reyes siempre eligieron para tales negocios a los "de la dicha nación vizcaína por averse hallado [...] en ellos puntualidad, verdad y fidelidad" (Suárez, 2001: 71). Tres virtudes que alimentaban un idealizado corolario atlántico que proporcionaba una pátina de confianza que favoreció la construcción de sus pequeños imperios mercantiles.

El argumento fue exitoso, si bien es cierto que la vida del banco de Plaza fue efímera (1621-1622) y que falleció quedando a deber mucha plata a la Hacienda Real. Este banquero vizcaíno mantuvo una íntima relación con la comunidad de emigrantes vascos de Lima, siendo incluso elegido mayordomo de la cofradía de Nuestra Señora de Aránzazu.

\section{Los conflictos entre naciones-patrias en la Monarquía compuesta}

El expurgo de la obra de Saavedra en tiempos de Felipe II activó a medio centenar de vizcaínos ubicados en las grandes ciudades de la Monarquía de los Habsburgo. Esta empresa se amplió a otros reinos peninsulares (Aragón, Valencia, Cataluña, Navarra, Galicia y Portugal) y ultramarinos (Perú y México). Tal acción política en defensa del buen nombre del Señorío y la hidalguía de sus naturales coronó la primera gran gestión colaborativa entre los emigrantes y sus autoridades en aras de la defensa de los intereses materiales y honoríficos de sus hijos en todos los confines de la monarquía española. La obligación de la reciprocidad entre hijos y casa-madre (provincia o Señoría) se torna en el lubricante de una acción defensiva a escala global protegiendo sus mutuos intereses jurídicos y económicos.

Si bien las familias generaron sus estrategias, por encima y/o en paralelo, las autoridades provinciales y regnícolas usaron a los naturales para obtener réditos políticos articulando una defensa de sus intereses mediante el sistema de representación creado en Madrid y Valladolid (Angulo, 2021: 295-316). Las agencias estables en Madrid y Valladolid como las diputaciones o embajadas coyunturales enviadas por los cuatro territorios a la Corte asumieron la defensa de sus principios jurídicos, la de sus hijos ante diversos conflictos y reforzaron sus posibilidades de éxito.

El Regimiento de Vizcaya de 3 de noviembre de 1638 -en el marco del sitio de Fuenterrabía y la defensa de la frontera con Francia- ordenó la edición en Valladolid de un impreso que pedía a sus hijos dejar ayudas financieras en beneficio del Señorío. El texto sostenía que "la obligación natural que cualquiera hijo, y los más notables tienen a su patria, que después de Dios, y el 
Rey es la primera, y a lo menos la segunda, después de los padres naturales". ${ }^{5}$ El Señorío señalaba tres propuestas a los emigrantes de Indias, Flandes o Italia: fundar dotaciones de doncellas, crear un colegio en Salamanca y mejorar la red viaria para fomentar el comercio (Merino, 2019: 127-152). Los receptores de la propuesta encajaban con el perfil visto en la Sevilla de 1590. Este documento redactado por un consultor, Francisco López de Echávarri, muestra el interés programático por contar con las riquezas de sus hijos en Flandes, Italia o Indias.

La casuística referida muestra la capacidad de las instituciones de Vizcaya en aras de defender su buen nombre, sus fueros y el posicionamiento de sus hijos en la Monarquía. Junto a estas propuestas colaborativas, el Seiscientos verá el surgimiento de otra línea de defensa frente a la presión de otras naciones-patrias, como la gallega (Irigoyen-García, 2013: 221-237). La edición de El Tordo Vizcayno -réplica al Búho Gallego- se produjo en 1638 (Mañaricúa, 1976; Fernández Albadalejo, 2007: 287-305). Este texto defendía la hidalguía y nobleza vizcaínas, sus fueros y su primacía en la Monarquía compuesta sosteniendo que:

"De aquí resulta aquella hermandad admirable entre los vizcaynos. No ay nación en el Orbe, adonde acampe más la unión, el afecto, el amor, el favorecerse unos a otros, el estimarse, no como paysanos, sino alimentados a unos mismos pechos. Aquella inclinación a la lengua, a la Patria; aquella piedad, aquel agasajo, aquella hermandad, aquella prontitud en darse las manos unos a otros, fundada en la identidad de sangre sin mixtura. Y el que es castizo vizcayno, aunque vea al otro descaído, no le desprecia, antes le ampara, favorece, le da la mano, le ayuda, le apadrina, le acredita y asegura su proceder; porque sabe que en la igualdad de la sangre no puede resultar distintos efectos. Puede ser que la fortuna a algunos sublime; pero los descaídos merecen la misma y que en todos hay igual obligación y correspondencia a tener la dicha del puesto [...] Adonde más ha florecido esta hermandad, es en la populosa y rica ciudad de Sevilla, a la que suscriben las partes peruanas y mexicanas [...] Pero reparo un sentimiento digno de remedio y es que en los tiempos antiguos un Secretario bastaba para introducir y dar la mano a muchos; un cargador para acreditar y enriquecer a otros; un Capitán, un Contador y un Ministro para blasonar lo mismo" (Mañaricúa, 1976: 141-143).

\footnotetext{
${ }_{5}^{5}$ Proposiciones que hace el Señorío de Vizcaya a los Cavalleros Vizcaynos sus hijos, que residen en las partes de las Indias, Flandes, Italia y otras Provincias. Valladolid, Antonio Vázquez de Velasco y Esparza, s. f., f. 2v.
} 
El anónimo subraya la cordialidad, mutuo respeto y auxilio, que se prestan sus naturales como hijos de una misma madre. Un amparo extendido a los menos afortunados, a quienes se protege y patrocina para obtener el puesto o empleo deseado. Era una realidad notoria en Sevilla, Nueva España o Perú. La escala imperial advertida en 1590 debería ser proyectada hasta el núcleo político y administrativo que pretendía gestionarlo, la Villa y Corte de Madrid. Todo ello contextualizado en una época de conflicto general entre las viejas naciones-patrias que aspiraban a gozar de mayor influencia y presencia en diversos ámbitos (estatales, universitarios, mercantiles y coloniales). En lo tocante a la cantera de oficiales de la Corona, los estudiantes salmantinos se organizaban en ocho naciones (Andalucía, Aragón, Campos, Extremadura, Galicia, La Mancha, Portugal y Vizcaya) vertebradas por el paisanaje y apoyadas por sus autoridades de origen. En el Seiscientos, bajo el manto de la "nación de Vizcaya" se agrupaba un elenco de alumnos de los distritos diocesanos de Calahorra y Pamplona. Es decir, las tres provincias (Álava, Guipúzcoa y Vizcaya), Navarra y La Rioja. La convivencia de estas naciones y, sobre todo, su intervención en las elecciones de catedráticos generó varios conflictos. En 1635 se produjo un choque entre estudiantes andaluces y vizcaínos. En los tumultos fallecieron dos vizcaínos, Domingo de Azpilaga y Martín de Araz (Hernández, 2016: 254). Solo la intervención regia y la mutilación de la mentalidad nacional acotaron esta dinámica de enfrentamiento entre las naciones estudiantiles.

También sabemos que la Real Chancillería de Valladolid guarda 262 causas comprendidas entre 1650 y 1680 donde el encausado declinaba la jurisdicción ordinaria a favor del Juez Mayor de Vizcaya. Los encausados eran varones vizcaínos presentes en ciudades castellanas y acusados de delitos contra personas, bienes, honor y orden público (Angulo, 2010: 33-72). Estas declinatorias descendieron conforme avanzaba la obtención de una certificación de vizcainía, es decir, de un documento jurídico que afirmaba el origen hidalgo del peticionario. Lo apreciamos como una excelente muestra de la toma de conciencia de la necesidad de prever las dificultades que la hidalguía por nacimiento les generaba al negociar, casarse o instalarse en otras lejanas zonas de la Monarquía compuesta.

Años antes del ejemplo navarro de crear una congregación en Madrid, en 1684, tenemos noticia del proyecto de Francisco de Zabala para las tres Provincias iniciado en 1677. Este fracasado plan (1677-1683) buscaba fijar en Madrid un hospital para los naturales de los tres territorios en la Corte. Zabala -agente del Señorío en Madrid (1668-1680)- subrayaba la protección del inmigrante que, sin oficio ni beneficio, acababa en la indigencia o delincuencia. El hospital y la congregación les ayudarían a retomar el camino hacia carreras (Angulo, 2016: 261-296) útiles para la Corona. Las Juntas alavesas atestiguan la lectura de una carta de José de Manurga con la propuesta de Zabala. El 
diputado general agradeció su interés mientras esperaba las medidas de las otras dos provincias. ${ }^{6}$ Lo cierto es que, en el surgimiento de las reales congregaciones de navarros y vascos en Madrid, los aparatos institucionales de los territorios de origen siempre estuvieron presentes.

Zabala fue objeto, entre 1647 y 1662, de sendos procesos judiciales que le llevaron a pedir una declinatoria de jurisdicción. La mayor concentración de tales actos jurídicos se produjo entre 1621 y 1680 -con 409 de procesos y un promedio anual de siete casos- que supone un $64 \%$ del total de demandas (Angulo, 2010: 56-58). Durante el reinado del primer borbón, el proyecto vasco se llevó a la práctica (1713-1718) mientras los navarros lo habían logrado en 1684. La presencia de delegados y/o embajadores de las provincias y Navarra en la Corte como estas asociaciones de naturales en Europa y América son claves en el éxito migratorio vasco (Angulo, 2016: 261-296). Una tupida red de cofradías y congregaciones en Madrid, Sevilla, México, Perú o Manila que ofrecía servicios, amparo e identidad a los emigrantes norteños.

En lo concerniente a los naturales del Reino de Navarra, sus expectativas de futuro mejoraron a mediados del Seiscientos. La negativa a la entrada del navarro José de Egües en el colegio vallisoletano de Santa Cruz por no ser castellano acabó con una Real Cédula (1647) que declaraba que los navarros "son de estos Reinos de Castilla, y que gozan de lo mismo que los que nacieron en ellos" (Martínez Aznal, 2016: 155). Ello incrementó su presencia en busca de oportunidades en el Imperio. Si un reducido grupo de familias constituía la élite política, militar y religiosa del Reino, para el resto de navarros las oportunidades nacían fuera del viejo Reino. Sin lugar a dudas, el mayorazgo, el estatus de hidalguía universal, la escasa productividad de la tierra o la fragmentación de la propiedad agrícola, sobre todo en valles pirenaicos y en la zona occidental navarra, avivaron el fenómeno migratorio (Baroja, 1969).

\section{¿Hombres o naciones enfrentándose por el control de la plata?}

La fiesta celebrada en Lima por la llegada de la imagen de Nuestra Señora de Aránzazu (Unzueta Echeverría, 1994: 343) es muestra palmaria de la unión de signos de identidad de emigrantes vascos y navarros en Indias. ${ }^{7}$ Esta presencia en eventos limeños se aprecia en 1638 con unos ochenta vizcaínos denominados la nación vascongada o un "lucido escuadrón de la nobleza de Vizcaya" participando en los festejos por la dedicación de la iglesia jesuítica de San Pablo en Lima (Cacho, 2016: 36). El impreso de 1647 se editó un lustro después de crear la hermandad limeña de Aránzazu formada por "los caballeros hidalgos

\footnotetext{
${ }^{6}$ ATHA, AJJGGA, Libro núm. 18, 05/05/1679, ff. 201v-202r.

7 Archivo de la Casa de Zavala. Legajo 247.9. Memoria de la forma de hacer la imagen de Nuestra Señora de Aranzazu para la capilla de la nación vascongada de la ciudad de los Reyes del Perú (Sevilla, 10 de marzo de 1644).
} 
de la nación vascongada". Tras presentarnos a la virgen y sus milagros, el autor relata el fervor y trabajo (cien mil pesos) de Juan de Urrutia, mayordomo de la cofradía limeña y rico hombre en Indias, para finalizar con la lujosa narración del ceremonial.

La descripción del traslado dibuja la presencia de los principales poderes de la capital virreinal en la procesión. El barroquismo mezclado con la catolicidad vasca (limpieza de sangre e hidalguía universal) retumban en un relato que deja rienda suelta a cuartetas, décimas, sonetos y villancicos en castellano y "bascuence". Las autoridades vieron el alborozo limeño de los vascos. Urrutia rebosaba de gozo, tal y como lo expresa el impreso: "Yre viosa esta cavisen conténtus gorpucéan [Su corazón no cabía de contento en el cuerpo]". El impreso alababa la capilla de la cofradía y mostraba a las monjas limeñas construyendo "vizcaínadas" de gran eco en la literatura castellana (Unzueta Echeverría, 1994: 350).

Los compatriotas de la villa Imperial de Potosí, vertebrados en una homónima cofradía, fueron protagonistas de la Guerra de vicuñas y vascongados entre 1620 y 1624 (Crespo, 1975). No dudaron en contactar con las autoridades provinciales y navarras para buscar apoyo en la Corte por medio de sus delegados (Otazu, 2008: 351-356). El factor cohesivo de los emigrantes norteños lo sostuvieron las asociaciones nacidas al calor del negocio de la plata (producción, transporte y acuñación) de Indias. Entre vascos y navarros surgen mineros y paisanos ligados a la extracción y comercialización (legal e ilegal) de la plata potosina (Alberdi, 2010: 175-188; Jiménez, 2015). De su membresía destacan los maestres de plata y compradores de metales preciosos (Angulo, 2012: 241-256). A ellos se unían los oficiales y jueces de la Corona que coadyuvaron al logro del control del tráfico de plata entre ambas orillas del Atlántico desde el Quinientos (Priotti, 2006: 25-40; Jiménez, 2015). La colaboración con la Corona les permitió contar habitualmente con el apoyo de sus instituciones y servidores en los conflictos en tierras peruanas.

El oropel de la plata escondía un malestar manifiesto en los disturbios potosinos que surgieron en tierras peruanas las siguientes décadas. La relación es significativa: Potosí (1622-1625), Caylloma (1629-1630), Chocaya (1634-1636), Carangas (1645), Lípes (1648-1650 y 1695), San Antonio de Esquilache (16521653 y 1665-1668) o Laicacota (1660-1661 y 1665-1668). Ocho localizaciones de la geografía minera del Perú y diez conflictos (con diversos orígenes, protagonistas y desenlaces) donde los vascos participaron defendiendo sus intereses y/o protegiendo su posición en el mercado argentífero (Numhauser, 2012: 117, 125-126). Fue el escenario de una guerra comercial por el control de los recursos argentíferos en la región de los Andes del Sur entre viejas naciones peninsulares. El sector vasco defendía su posición oligopólica dominante en este sector (Lorandi, 2000: 111-135). La defensa de la bien o mal ganada posición 
de vascos y navarros en el mercado de los metales preciosos acabó chocando con el resto de naciones peninsulares.

La defensa de los paisanos (Kintana, 2002: 287-310; Hausberger, 2013: 173-192) la acometieron las provincias vascas y Navarra en respuesta a las demandas de sus hijos (Otazu, 2008: 351-356). Desde la ciudad de la Plata, en 1623, los emigrantes pedían a sus autoridades en la Península que:

“...algunos hombres desalmados que a título de provincias españolas an lebantado bandera haciendo juntas confederados entre si pasa hazer y causar una notable persecución contra los hijos de Vuestra Señoria del nobilisimo señorio de Vizcaya, provincia de Alava y Reino de Navarra, que sin distincion hermanados en estos estendidos reynos de las indias con amor y benebolencia nos llamamos vascongados nos a constreñido con maduro acuerdo como a madre tan piadosa y que tambien sabe poner los medios necesarios para acrecentamiento y honra de los suyos". 8

Estos vástagos buscaron el apoyo de sus autoridades como contraprestación a sus servicios. El parlamento alavés pidió así al doctor y abogado Laurencio de Vidania asumir las diligencias sobre la defensa en Corte de los provincianos por las vejaciones sufridas. ${ }^{9}$ La junta alavesa les defendió de tales vejaciones en la Corte junto a Guipúzcoa, Vizcaya o Navarra. El agente alavés en Madrid y Vidania lograron que la investigación y sentencia dejasen en buen lugar a la nación vascongada. El notorio éxito de vascongados y navarros afectados por otras naciones en la contienda por el control de la plata peruana se aprecia en el Puno de la década de 1660 (Maiza, 1991: 343-35). Nuevamente, los parlamentarios alaveses recibieron cartas desde América informando de persecuciones y malos tratos por otras naciones y solicitando el amparo alavés; eso sí, encargándose ellos de los gastos de la defensa cortesana. ${ }^{10}$

En Vizcaya, la Junta General de Guernica de noviembre de 1667 recoge un relato de los delitos de esas naciones en Perú con el resultado final de varias muertes violentas -como en Salamanca o Potosí. La relación llegó a través de una carta:

“...firmada de mano de muchos hijos de su señoría residentes en el reyno del Piru y diferentes relaciones por las cuales dan quenta a su señoría que, habiendose echo uno la nación andaluça y estremeña con los yndios mestiços, acaudillándolos Joseph y Gaspar de Salcedo, hermanos, se habían levantado con muchas minas pertenecientes a hijos de su señoria y a los

\footnotetext{
8 Archivo General de Guipúzcoa [AGG] Juntas y Diputaciones. IT, 4063, 5, f. 1 v.

${ }_{9}$ ATHA, AJJGG., Libro no 10, 18/11/1624, ff. 33r.-33v.

${ }^{10}$ ATHA, AJJGG., Libro nำ 17, 18/11/1667, ff. 264v-265r.
} 
naturales del reyno de Navarra y Probincia de Gupuscoa y Alaba, no contentos con el dicho lebantamiento en perjuicio de su magestad y su regalia, havían apellidado libertad y se abian determinado a sustentarlo por armas y, abiendose puesto en defensa, abian muerto muchos ministros de su magestad y naturales de las dichas tres provincias e hijos de su señoria" (Sesmero, 2004: 248).

La carta la firmó en Lima el general Diego Ordoño de Sarricolea y Zamudio. Iba acompañada de otra misiva redactada en Madrid por un sobrino suyo, Pedro de Bolumburu y Sarricolea. Al igual que en Álava, el parlamento vizcaíno alargó su amparo ante la Corona. El Señorío comisionó al Corregidor y a los Diputados Generales para darse la mano con las otras dos provincias y Navarra pidiendo castigo contra los sediciosos ante los Reales Consejos y Carlos II. Para adelantar tal súplica en Madrid fue vital la mediación de su agente, Juan Francisco de Goiri y Arteche, junto a un abogado de los Reales Consejos y consultor del Señorío, Diego de Sarricolea y Zamudio (Sesmero, 2004: 404-405). Las actas parlamentarias citan al alférez real Martín Ruiz de Gareca Isuquiza (caballero de Santiago), al general Antonio de Butrón y al contador Francisco de Burgoa, los tres presos en las cárceles limeñas. En Lima los defensores serían Diego Ordoño de Sarrciolea y Pedro de Lezama.

Un lustro más tarde, el 12 de octubre de 1672, las juntas vizcaínas trataron de nuevo esta cuestión. El pleito seguía pendiente en el Consejo de Indias. El nuevo agente, Francisco de Zabala, gestionaba contra el memorial de los Salcedo (Martínez Lahidalga, 2004: 36). La colaboración entre Navarra y las Provincias produjo un memorial impreso que corrió por Madrid, Sevilla o Lima. ${ }^{11}$ Una lucha de la que, finalmente, salió victorioso el institutional entangled global network de vascongados y navarros pocos años antes de que, por primera vez, los últimos - con el plácet del Reino de Navarra- creasen en Madrid la Real Congregación de San Fermín de los Navarros.

\section{Conclusiones}

Las familias y sus estrategias han ocupado gran atención las últimas décadas. Esta visión historiográfica de alto contenido teórico y bajo peso documental (Yun, 2002: 261), claro sesgo conservador y próxima a argumentos antinacionalistas, ubica en el mundo familiar un nuevo paradigma histórico

\footnotetext{
${ }^{11}$ Memorial y relación que el antiquísimo Reyno de Navarra y las Nobilissimas Prouincias de Guipuzcua, Vizcaya, y Alaua, presentan à la Reyna nuestra Señora en su Real Consejo de Indias, satisfaciendo à los siniestros informes, que con titulo de defensa de Gaspar de Salcedo, se han esparcido, y presentado por su parte, en graue perjuizio de los leales vasallos de su Magestad, y especialmente de los Vascongados, que assiestieron à las Iusticias en los Reynos del Perù, con ocasión de los disturbios de Puno. Biblioteca Colombina y Capitular de Sevilla. Sign. 33-5-22-009.
} 
que, intencionadamente, oculta o elimina, otras construcciones históricas expuestas en este trabajo. Sin embargo, la retórica familiar no es exclusiva del ámbito doméstico, sino que, al menos en las provincias vascas, se asumió el corolario familiar como vía definitoria de las relaciones entre sus instituciones políticas y la legión de emigrantes asentados en el seno de una monarquía tejida de Reinos y repúblicas compuestas.

Amparados en el principio político de la reciprocidad -do ut des- los emigrantes (primogénitos y/o segundones) de la nobleza vasca y navarra contaron en todo momento con mecanismos propios -redes de sociabilidad y defensa como fueron las cofradías y congregaciones-, con un espíritu ligado al concepto de naciones-patrias así como con el auxilio de las autoridades de sus lugares de origen. La profunda y estrecha colaboración entre emigrantes, asociaciones devocionales y asistenciales que generaron en los lugares de asentamiento y la perpetua presencia e influencia de las autoridades territoriales de sus lugares de origen a través de su sistema de agencias en Corte ayudaron de manera directa y fundamental al mantenimiento de una imagen exitosa del emigrante vasco y navarro del Seiscientos. La cercanía y alta influencia cerca de la Corona y sus consejeros será otra clave del éxito. Unos bien considerados servidores de los Habsburgo enfrentados a otras naciones de origen medieval.

Ora en el amparo de la hidalguía universal (principal riqueza de estos emigrantes) ora en la defensa de sus naturales involucrados en los conflictos surgidos en torno a la explotación de los recursos argentíferos del Perú, las autoridades de los lugares de origen y la legión de emigrantes buscaron la mutua colaboración. Aunque esta realidad pervivió en el Setecientos, la más efectiva presión de los Borbones limitó la capacidad de acción de estos institutional entangled global networks (Angulo, 2016: 261-296); eso sí, sin eliminarlos.

\section{Bibliografía citada}

Achón, José Antonio (2001). “La 'Casa Guipúzcoa': sobre cómo una comunidad territorial llegó a concebirse en términos domésticos durante el Antiguo Régimen", en Imízcoz, José M. (coord.) Redes familiares y patronazgo: aproximación al entramado social del País Vasco y Navarra en el Antiguo Régimen (siglos XV-XIX), Bilbao: Universidad del País Vasco, pp. 113-138.

Albareda, Joaquim y Herrero, Manuel (eds.) (2018). Political representation in the Ancien Régime, London/New York: Routledge.

Álvarez, Óscar; Angulo, Alberto y Ramos, Jon Ander (coords.) (2014). Devoción, paisanaje e identidad. Las cofradías y congregaciones de naturales en España y en América (siglos XVI-XIX), Bilbao: Universidad del País Vasco. 
Álvarez, Óscar y Arrieta, Idoia (2004). Las huellas de Aránzazu en América, Donostia: Eusko Ikaskuntza.

Alberdi, Xavier (2010). "Las redes comerciales guipuzcoanas en la conformación del tráfico de la plata peruana a través del puerto de Buenos Aires: los casos de Maleo y de Martiarena", en Paniagua, Jesús y Salazar, Nuria (coords.) Ophir en las Indias: estudios sobre la plata americana: siglos XVI-XIX, León: Universidad de León, pp. 175-188

Angulo, Alberto (2010). “'Otro imposible vencido': hombres, provincias y reinos en la Corte en tiempos de Carlos II", en Torres, Rafael (coord.) Volver a la hora navarra: la contribución navarra a la construcción de la monarquía española en el siglo XVIII, Pamplona: Eunsa, pp. 33-72.

Angulo, Alberto (2012). "Mercados y financieros vascos: el circuito de la plata y su control en el seiscientos", en García, Ernesto (coord.) Tesoreros, arrendadores y financieros en los reinos hispánicos: la Corona de Castilla y el Reino de Navarra (siglos XIX-XVII), Madrid: Instituto de Estudios Fiscales, pp. 241-256.

Angulo, Alberto (2015). “Los frutos de la movilidad. La emigración norteña peninsular en Madrid y el Imperio (siglos XVII y XVIII)", Obradoiro de historia moderna, núm. 24, pp. 113-139.

Angulo, Alberto (2016). "Los hidalgos norteños en el centro de un Imperio: Madrid (1638-1850). Negocios, política e identidad", en Angulo, Alberto y Aragón, Álvaro (coords.) Recuperando el Norte: empresas, capitales y proyectos atlánticos en la economía imperial hispánica, Bilbao: Universidad del País Vasco, pp. 261-296.

Angulo, Alberto (2017). “Orden y desorden familiar en la emigración. El asociacionismo del norte peninsular (siglos XVII-XVIII)", en Rey, Ofelia y Cowen, M. Pablo (coords.) Familias en el Viejo y el Nuevo Mundo, Buenos Aires: Universidad Nacional de la Plata, pp. 113-133.

Angulo, Alberto (2019). “Ubicarse en la Corte. La presencia institucional y diplomática vasca en el corazón de la Monarquía Hispánica (XVI-XIX)", en Martínez, José et al. (coords.) Del enfrentamiento a la amistad. Influencias entre las Monarquías de Francia y España en los siglos XVII y XVIII, Madrid: Polifemo, pp. 427-458.

Angulo, Alberto (2021). "Representación y negociación. Agencias y embajadores provinciales de los parlamentos en el Madrid del Seiscientos", en Bravo, Cristina y Álvarez-Ossorio, Antonio Los embajadores. Representantes de la soberanía, garantes del equilibrio (1659-1748), Madrid: Marcial Pons Historia, pp. 295-316.

Angulo, Alberto y Merino, Imanol (2012). “La gestión del Señorío de Vizcaya en el Imperio (1590-1640). La proyección de su representación y defensa", en 
Pérez, M. José y Martín, Alfredo (eds.) Campo y campesinos en la España Moderna. Culturas políticas en el mundo hispano, León: Universidad, pp. 1781-1791.

Aragón, Álvaro (2019). “French Basque and Béarnais trade diaspora from the Spanish Basque Country during the eighteenth century", Atlantic Studies, núm. 16/4, pp. 452-481.

Arrieta, Jon (2014), "Nobles, libres e iguales, pero mercaderes, ferrones... y frailes: en torno a la historiografía sobre la hidalguía universal", Anuario de historia del derecho español, núm. 84, pp. 792-842.

Baroja, Julio C. (1985). La Hora navarra del siglo XVIII. Personas, familias, ideas, Pamplona: Gobierno de Navarra.

Cacho, Rodrigo (2016). "Carta que un amigo escribe a otro: relación poética inédita de la dedicación de la iglesia jesuítica de San Pablo (Lima, 1638)", Nueva revista de filología hispánica, núm. 1, pp. 27-89.

Cardim, Pedro; Herzog, Tamar; Ruiz, José Javier \& Sabatini, Gaetano (eds.) (2012). Polycentric monarchies. How did Early Modern Spain and Portugal Achieve and Maintain a Global Hegemony?, Eastbourne (UK): Sussex Academic Press.

Crespo, Alberto (1975). La guerra entre vicuñas y vascongados, Potosí 1622-1625, La Paz: Librería Editorial Juventud.

Dincecco, Mark (2010). "Fragmented authority from Ancien Régime to modernity: a quantitative analysis", Journal of Institutional Economics, 6 (03), 305328.

Donézar, Javier M. (2004). “De las naciones-patrias a la 'nación-patria'. Del Antiguo al Nuevo Régimen", en García, Bernardo José y Álvarez-Ossorio, Antonio (coords.) La monarquía de las naciones: patria, nación y naturaleza en la monarquía de España, Madrid: Fundación Carlos de Amberes, pp. 93-120.

Fernández, Pablo (2007). Materia de España: cultura política e identidad en la España moderna, Madrid: Marcial Pons.

Fernández, Fernando (2000). Comerciantes vascos en Sevilla, 1650-1700. Vitoria: Gobierno Vasco.

Gaudin, Guillaume (2017). El imperio de papel de Juan Díez de la Calle. Pensar y gobernar el Nuevo en el siglo XVII, Madrid: Fondo de Cultura Económica.

Greene, Jack P. (2002). "Transatlantic colonization and the redefinition of Empire in the Early Modern Era", en Daniels, Christine et al. (eds.), Negotiated Empires: Centers and Peripheries in the Americas, 1500-1820, New York: Routledge, pp. 267-282.

Hausberger, Bernd (2013). “Paisanos. La etnicidad de los vascos en Potosí, c. 1600-1625", Caravelle, núm. 101, pp. 173-192. 
Hernández, Gustavo (2016). “¿Guerra de naciones? Movilización política, conflictividades y violencias entre naciones universitarias en la Salamanca del periodo Barroco", CIAN-Revista de Historia de las Universidades, núm. 19/2, pp. 243-264.

Herrero, Manuel (2017). Republicas y republicanismo en la Europa moderna (siglos XVI-XVIII), Madrid: Fondo de Cultura Económica.

Herzog, Tamar (2000). "Private Organizations and Global Networks in Early Modern Spain and Spanish America", en Roniger, Louis \& Herzog, Tamar (eds.) The collective and the public in Latin America: Cultural identities and political order, Brighton: Sussex Academic Press, pp. 117-133.

Irigoyen-García, Javier (2013). “Discursos patriótico-aristocráticos sobre la 'nación gallega' a comienzos del siglo XVII: a propósito de Tragedias de amor (1607) de Juan de Arce Solórzano", Journal of Spanish Cultural Studies, núm. 3, pp. 221-237.

Jiménez, Ismael (2015). Poder y corrupción administrativa en el Perú colonial (16601705), Sevilla: Universidad de Sevilla.

Kintana, Jurgi (2002). “La 'nación bascongada' y sus luchas en el Potosí del siglo XVII. Fuentes de estudio y estado de la cuestión", Anuario de Estudios Americanos, núm. 1, pp. 287-310.

Larramendi, Manuel de (1983). Conferencias curiosas, politicas, legales y morales sobre los Fueros de la Provincia de Guipúzcoa (1756-1758), San Sebastián: Diputación de Guipúzcoa.

Lorandi, Ana María (2000). "Identidades ambiguas. Movilidad social y conflictos en los Andes, siglo XVII", Anuario de Estudios Americanos, núm. 1, pp. 111-135.

Madariaga, Juan (2012). Apologistas y detractores de la lengua vasca, San Sebastián: Fundación para el Estudio del Derecho Histórico y Autonómico de Vasconia.

Maiza, Carlos y Oreja, José M. (1991). “Izacota: revuelta en una mina peruana (1665-1671)", Príncipe de Viana. Anejo, núm. 13, pp. 343-351.

Mañaricúa, Andrés de (1976). Polémica sobre Vizcaya en el siglo XVII. El Búho Gallego y el Tordo Vizcayno, Bilbao: La Gran Enciclopedia Vasca.

Martínez, Rubén (2016). “El agente del Reino de Navarra en la Corte y la Real Congregación de San Fermín. Dos formas de una misma representación", en Angulo, Alberto y Aragón, Álvaro (coords.) Recuperando el Norte: empresas, capitales y proyectos atlánticos en la economía imperial hispánica, Bilbao: Universidad del País Vasco, pp. 143-168.

Martínez, Adela et al. (2004). Juntas y Regimientos de Bizkaia. Actas. Tomo XVII (Mayo 1672-Noviembre 1678), Bilbao: Juntas Generales de Bizkaia. 
Merino, Imanol (2019). “'Hacer mayorazgo infalible de consejeros y ministros graves'. El Señorío de Vizcaya y el proyecto de fundar un colegio en Salamanca (1638-c. 1660)", CIAN. Revista de historia de las universidades, núm. 2, pp. 127-152.

Numhauser, Paulina (2012). “Un asunto banal. Las luchas de vicuñas y vascongados en Potosí (siglo XVII)”, Illes, Imperis, núm. 14, pp. 113-138.

Otazu, Alfonso de y Díaz de Durana, José Ramón (2008). El espíritu emprendedor de los vascos, Madrid: Sílex.

Pérez, Jorge (2014). “El éxito social entre los emigrantes peninsulares en el Perú: integración, prestigio y memoria”, Cuadernos Dieciochistas, núm. 15, pp. 241-275.

Priotti, Jean-Philippe (2006). "Metales preciosos, competencia comercial y transformación económica en el Atlántico franco-español (1550-1570)", Jahrbuch für Geschichte Lateinamerikas, núm. 43, pp. 25-40.

Rubio, Francisco Javier (2020). La república de sabios. Profesores, cátedras y universidad en la Salamanca del Siglo de Oro, Madrid: Universidad Carlos III.

Sesmero, Enriqueta et al. (2004). Juntas y Regimientos de Bizkaia. Actas. Tomo XVI (Noviembre 1664-Febrero 1672), Bilbao: Juntas Generales de Bizkaia.

Suárez, Margarita (2001). Desafíos transatlánticos. Mercaderes, banqueros y el estado en el Perú Virreinal, 1600-1700, Lima: IFEA.

Unzueta, Antonio (1994). "Fragmentos euskéricos en un libro desconocido sobre la Virgen de Aránzazu", Sancho el Sabio: revista de cultura e investigación vasca, núm. 4, pp. 343-352.

Yun,-Casalilla, Bartolomé (2019). Historia global, historia transnacional e historia de los imperios. El Atlántico, América y Europa (siglos XVI-XVIII), Zaragoza: Institución Fernando el Católico.

Yun-Casalilla, Bartolomé (2020). “De imperios, globalizaciones y el oficio del historiador: entrevista a Bartolomé Yun-Casalilla", Humanidades: revista de la Universidad de Montevideo, núm. 7, pp. 253-265. 